(C) 2018. This manuscript version is made available under the CC-BY-NC-ND 4.0

license http://creativecommons.org/licenses/by-nc-nd/4.0/

\title{
Suicidal attempts among patients with substance use disorders who present with suicidal ideation
}

José J. López-Goñi ${ }^{1}$, Javier Fernández-Montalvo ${ }^{1}$, Alfonso Arteaga ${ }^{1}$, and Begoña Haro ${ }^{1}$

${ }^{1}$ Departamento de Ciencias de la Salud.

Universidad Pública de Navarra.

31006 Pamplona. Spain

Running head: Addiction and suicide

Corresponding author: José J. López-Goñi. Departamento de Ciencias de la Salud.

Universidad Pública de Navarra 31006 Pamplona (Spain). Phone: 0034948169243.

Email: josejavier.lopez@unavarra.es

José J. López-Goñi, Javier Fernández-Montalvo, Alfonso Arteaga, Begoña Haro, (2019).

Suicidal attempts among patients with substance use disorders who present with suicidal

ideation. Addictive Behaviors 89, 5-9

https://doi.org/10.1016/j.addbeh.2018.09.006 


\section{ABSTRACT}

Background and aims: Patients with addictions have a great risk of suicidal ideation and attempts. Suicidal behaviour is a continuum that begins with ideation and may continue with planning, attempts and suicide completion. Investigating the specific risk characteristics for suicidal attempts in patients with addiction problems who present with suicidal ideation is crucial for developing prevention strategies. The main aims of this study were to determine the prevalence rate of suicide attempts among patients with lifetime suicidal ideation receiving treatment for addiction, and to explore the differential characteristics for suicide ideators with and without suicide attempts. Methods: A sample of 149 patients with suicidal ideation (110 male and 39 female) who sought treatment for addiction in a Spanish clinical centre was assessed. Measurements: Information concerning socio-demographic characteristics, addiction severity, and psychopathological symptoms was obtained. Results: In total, 39.6\% of the patients had attempted suicide (95\% Confidence Interval: 32.1\%-47.6\%). Although all patients with suicidal behaviours presented a high severity in their addiction, patients with both suicidal ideation and suicide attempts showed a more severe addiction profile and more maladjustment to everyday life than patients with only suicidal ideation. Specifically, three psychopathological variables were related to suicide attempts: worse psychiatric state, previous hospitalization for psychological problems, and history of delirium. Conclusions: According to the results, a systematic screening of suicidal risk in patients seeking treatment for addiction problems is recommended. Addiction treatment centres should develop treatment strategies to prevent suicidal ideators from attempting suicide, mainly in those cases with a worse lifetime psychiatric condition.

Keywords: drug addiction; suicidal ideation; suicide attempts; assessment; prevalence 


\section{INTRODUCTION}

In recent years, several studies have shown a high frequency of suicidal behaviours in patients with addiction problems (Darvishi et al., 2015; Hung et al., 2013; Vaszari et al., 2011; Yuodelis-Flores and Ries, 2015). The results of these studies show that the prevalence rates of suicidal behaviours in patients with addiction problems are higher than those of the general population, especially in patients with greater associated problems, as, for example, psychopathological comorbidity, lifetime abuse, or childhood traumatic events (Arribas-Ibar et al., 2017; Fernández-Montalvo et al., 2015; Rodriguez-Cintas et al., 2018; Roy, 2010). Moreover, recent studies in the addiction field show that patients with suicidal behaviours present a more severe clinical profile (Darke et al., 2010; Fernández-Montalvo et al., in press).

Suicidal behaviour is considered a continuum that begins with suicidal ideation and may continue with planning, attempts and suicide completion (Yuodelis-Flores and Ries, 2015). In the addiction field, several recent studies have compared the differential characteristics of patients with and without suicidal ideation (Arribas-Ibar et al., 2017; Vaszari et al., 2011), and of patients with and without suicide attempts (Hung et al., 2013; Roy, 2001, 2002, 2003). The results show relevant differences between patients with and without suicidal behaviours. If suicidal behaviour is understood as a continuum (Yuodelis-Flores and Ries, 2015), it becomes crucial to study the differential profiles of patients in the various stages of suicidal behaviour (ideation, planning, attempt, and suicide completion) in order to tailor prevention programmes to those profiles.

However, to the best of the researchers' knowledge, there are no previous studies investigating specific differences between patients with only suicidal ideation and those who have also attempted suicide in the addiction context. These types of 
studies are essential for two reasons: first, suicidal ideation and attempts constitute two consecutive steps in the suicide continuum, and second, knowing the specific risk characteristics for suicidal attempts in patients who present with suicidal ideation is a crucial clinical issue to develop prevention strategies. Consequently, a systematic screening of suicidal risk when assessing patients in drug-addiction clinical settings is needed. Therefore, the main aims of this study were, first, to determine the prevalence rate of suicide attempts among patients with lifetime suicidal ideation receiving treatment for addiction, and second, to explore the differential characteristics (sociodemographics, addiction severity, psychopathological symptoms, and maladjustment variables) for suicide ideators with and without suicide attempts. The primary hypothesis of this study is that suicide attempters among patients with suicidal ideation will present a more severe addiction profile and more associated psychopathological symptoms compared to those ideators without suicide attempts.

\section{METHODS}

The protocol for this study was approved by the ethics committees of the Universidad Pública de Navarra (PI-006/16) and of the Fundación Proyecto Hombre de Navarra (PHN2016-01). Informed consent was written and signed by all participants.

\subsection{Participants}

The initial sample consisted of 375 consecutive patients who sought treatment for addiction in one of the two programmes (outpatient and inpatient) of the Proyecto Hombre Navarra Foundation (Spain). These programmes have a cognitive behavioural basis and are geared towards abstinence. They are public and attend to patients who are representative of Spanish patients with addiction problems. Both outpatient and inpatient modalities have been effective in the treatment of addiction (FernándezMontalvo and López-Goñi, 2010; Fernández-Montalvo et al., 2008) 
The inclusion criteria for this study were a) fulfilling the diagnostic criteria of alcohol and/ or substance use disorders of the DSM-5 (American Psychiatric Association, 2013); b) being in the age range of 18 to 65 years; c) presenting with lifetime suicidal ideation; and d) signing an informed consent form to be part of the study.

One hundred and eighty-five (55.4\%) of the 334 initial subjects did not meet the third criterion related to the presence of lifetime suicidal ideation. The rest of the sample met all criteria and therefore were included in the study $(n=149 ; 44.6 \%)$. One hundred and ten were men (73.8\%), and 39 (26.2\%) were women. The mean age of subjects was 37.6 years $(\mathrm{SD}=8.5$ years). The main substances of consumption were alcohol $(49 \%)$ and cocaine (43\%) followed by other substances (e.g., heroin, cannabis, and amphetamine) at a smaller percentage (8.1\%).

\subsection{Instruments}

The EuropASI (Kokkevi and Hartgers, 1995) is the European version of the Addiction Severity Index scale (ASI) (McLellan et al., 1980). The Spanish version used is by Bobes, González, Sáiz, and Bousoño (1996). This interview assesses the need for patient treatment based on seven different areas: a) general medical condition; b) employment and financial situation; c) alcohol consumption; d) use of other drugs; e) legal problems; f) family and social relationships; and g) psychiatric state. The Interviewer Severity Rating (ISR), which has demonstrated good predictive validity in different studies conducted in the treatment context (Lopez-Goni et al., 2012; LópezGoñi et al., 2010), was used. The score for each area ranges from 0 (no problem) to 9 (extreme problem). The higher the score is, the greater the need for treatment is. For the assessment of the global prevalence of both lifetime suicidal ideation and attempts, two specific items of the EuropASI Psychiatric area were used: 9 ("Did you experience 
severe suicidal ideation?”) and 10 (“Did you make suicide attempts?”). In addition, several items of the EuropASI were used to obtain information about the presence of alcohol/drugs related problems (Drug and alcohol use scale: items 1, 7, 15 and 18), medical problems (Medical scale: items 3 and 8), psychopathological problems (Psychiatric scale: items 1, 3, 4, 6, 7, 8, 9 and 10), and the level of adjustment in the familial sphere (Family and social scale: item 9).

The Symptom Checklist-90-Revised (SCL-90-R) (Derogatis, 1992) (Spanish version by González de Rivera, 2002) is a self-administered general psychopathological assessment questionnaire. This checklist consists of 90 questions that are answered on a 5-point Likert-type scale, ranging from 0 (none) to 4 (very much). The questionnaire aims to assess the respondent's psychiatric symptoms. The SCL-90-R has been shown to be sensitive to therapeutic change and thus may be used for either single or repeated assessments. The SCL-90-R measures nine areas of primary symptoms: somatisation, obsession-compulsion, interpersonal sensitivity, depression, anxiety, hostility, phobic anxiety, paranoid ideation and psychoticism. The questionnaire also provides three indices that reflect the subject's overall level of severity: Global Severity Index (GSI), Positive Symptoms Distress Index (PSDI) and Positive Symptom Total (PST).

\subsection{Design}

A cross-sectional design was used. Specifically, a retrospective ex post facto study was conducted.

\subsection{Procedure}

Once the clinical sample was selected using the criteria described above, the assessment of the sample was performed in two sessions before beginning the treatment for addiction. All patients were interviewed by clinical psychologists who had ten or more years of experience in assessing and treating addictions. Self-report measures were 
administered with the presence and support of the interviewers. Each session occurred once a week. In the first session, data related to socio-demographic characteristics (age, gender and marital status), drug consumption, and lifetime suicidal thoughts and attempts were collected using the EuropASI. In the second session, the presence of psychopathological symptoms was assessed using the SCL-90-R.

In this study, two mutually exclusive groups were studied: a) only suicidal ideation, and b) suicidal ideation + suicide attempts.

\subsection{Data analysis}

Descriptive analyses were performed for all variables. In the bivariate analyses between the two groups, $\chi^{2}$ or the Student's $t$ test for independent samples were used, depending on the nature of the variables analysed. The t-test was used because data presented a random distribution (assessed by Runs test for randomness), and the size of the smallest subsample was higher than 40 . The statistical analyses were two-sided. Effect sizes (Cohen's $d$ or $w$ ) and statistical power (alpha $=0.05$ ) for the analyses were provided, taking into account Cohen's recommendation: $d=0.20$ (small effect size), $d=$ 0.50 (medium effect size), and $d=0.80$ (large effect size). Regarding multivariate analysis, one logistic regression analysis (step-by-step forward method) was conducted to determine which specific factors were the most relevant for differentiating between the groups studied. All statistically significant variables in the bivariate comparisons were included in the logistic regression analysis. The dependent variable was the presence/absence of suicide attempts. The variable entry criterion was set to 0.05 and the variable retention criterion to 0.10 . The Hosmer-Lemeshow test was used to assess the goodness of fit of the model. A difference of $p<.05$ was considered significant. All statistical analyses were performed using SPSS (v. 24.0) software.

\section{RESULTS}

José J. López-Goñi, Javier Fernández-Montalvo, Alfonso Arteaga, Begoña Haro, (2019). Suicidal attempts among patients with substance use disorders who present with suicidal ideation. Addictive Behaviors 89, 5-9 


\subsection{Prevalence of suicide attempts in patients with suicidal ideation}

The prevalence of suicide attempts among the 149 patients with suicidal ideation was 39.6\% ( $n=59$; 95\% Confidence Interval: 32.1\% - 47.6\%). No gender differences between patients with and without suicide attempts were found (Table 1).

\section{PLACE TABLE 1 HERE}

\subsection{Comparisons between patients with and without suicide attempts}

No statistically significant differences between groups were found in age, marital status, substance of consumption and years of consumption (Table 1). However, patients with suicide attempts presented a higher rate of delirium tremens and overdoses. Moreover, from an addiction severity perspective, these patients showed a more severe profile in four areas of the EuropASI: employment/ support, alcohol consumption, family/ social support, and psychiatric state. Regarding associated psychopathological symptoms, significant differences were only observed in phobic anxiety, with higher scores being observed in patients with suicide attempts.

On the other hand, comparisons in maladjustment variables showed several statistically significant differences (Table 2). Specifically, patients with suicide attempts presented a higher rate of prescribed medication for physical problems. Moreover, these patients more frequently lacked close and long-lasting relationships with their partner and/ or children. From a psychological point of view, the patients showed more anxiety and depression problems, had received more psychopharmacological treatments, and had been hospitalized more times for psychological problems.

\section{PLACE TABLE 2 HERE}

\subsection{Variables related to the type of suicide behaviour}


Once the differences between both groups were observed, a logistic regression analysis was carried out in order to know the role of the different variables in the two groups: a) suicidal ideation and b) suicidal ideation + suicide attempts.

The results from the logistic regression analysis showed that having experienced delirium tremens, having been hospitalized for psychological problems, and having a greater severity in the EuropASI psychiatric scale were the primary variables related to suicide attempt among patients with suicidal ideation (Table 3).

\section{PLACE TABLE 3 HERE}

\section{DISCUSSION}

In this study, the prevalence of suicide attempts among patients with lifetime suicidal ideation seeking treatment for addiction problems was explored. This study is the first conducted in Spain to address the specific differences between patients with only suicidal ideation and patients with both suicidal ideation and suicide attempts in addiction treatment centres. The results from this study showed that the rate of ideators who attempted suicide was a prevalent phenomenon (39.6\%; 95\% Confidence Interval: $32.1 \%$ - 47.6\%). The high prevalence of suicidal behaviours in addictions is welldocumented (Arribas-Ibar et al., 2017; Darvishi et al., 2015; Hung et al., 2013; Rodriguez-Cintas et al., 2018; Roy, 2010; Vaszari et al., 2011; Yuodelis-Flores and Ries, 2015), but this study is focused on understanding factors related to the different stages of suicidal behaviour as a continuum from ideation to attempt. Most of the studies conducted to date compare patients with and without suicidal ideation or patients with and without suicide attempts (Rodriguez-Cintas et al., 2018; Roy, 2009, 2010; Vaszari et al., 2011). The lack of specific studies in the addiction field of ideators who attempt suicide has prevented us from comparing results. 
All patients included in this study had a severe clinical profile, since all of them presented suicidal ideation. As has been observed in other studies, patients with suicidal ideation tend to present a higher level of severity in both addiction and associated variables (Garlow et al., 2003; Vaszari et al., 2011). In our study, the analysis of the specific profile of those ideators who attempted suicide revealed an even greater severity with a higher frequency of delirium tremens and overdoses and a worse addiction profile. Moreover, the ideators suffered more frequently from physical and psychological problems. Therefore, these data support the existence of specific characteristics in the different stages of the suicide continuum. It could be hypothesized that patients with a more severe addiction profile are suffering a larger number of negative consequences, with more difficulties to cope with, and, consequently, they go further in the suicide behaviours continuum as a way of ending their suffer. Anyway, this constitutes only one hypothesis that should be addressed in future studies.

On the other hand, the characteristics found in this study for ideators who attempt suicide (e.g., more employment difficulties, less family and social support, worse psychopathological state, and more associated problems) are frequently related to an unsuccessful therapeutic progression in the treatment of the addiction problem (Cacciola et al., 2009; Fernández-Montalvo and López-Goñi, 2010; López-Goñi et al., 2012; López-Goñi et al., 2014; Moos et al., 2001). From this perspective, success in addiction treatment would itself constitute a preventive intervention for suicide attempts. Therefore, the design of treatment retention strategies to avoid the high attrition rates in addiction programmes may be a way of preventing suicidal behaviours in patients with addiction problems.

The present study has a number of limitations. First, the exploratory nature of this study means that the specific causal role of the explored risk factors cannot be established. 
Second, our study included patients from only one treatment centre in Spain, which might create a bias that prevents us from generalizing the results. Future studies should include larger samples in other settings and countries. Third, one aspect that should be considered is the distribution of the sample by gender, as only small number of women were included. Although this gender imbalance is a common circumstance in most addiction studies, it should be taken into account when generalizing the obtained results. Finally, in this study, only two stages of suicidal behaviour were considered: ideation and attempt. Future studies should analyse the characteristics of patients in other stages of the suicide continuum in order to tailor addiction treatment programmes to them. These limitations might influence the findings and must be considered in further research.

Nevertheless, the results of this study show that a high rate of patients in addiction treatment programmes have suicidal ideation. Moreover, a high rate of ideators attempt suicide; these attempters present with a more severe addiction profile with more associated physical and psychological problems. Therefore, it seems that there are differential characteristics associated with the different stages of suicidal behaviour. According to these results, to develop treatment strategies to prevent suicidal ideators from attempting suicide, the specific suicide risk should be systematically screened in suicidal ideators seeking treatment for addiction.

\section{ACKNOWLEDGEMENTS}

The authors would like to thank the "Proyecto Hombre de Navarra" programme staff for their help in assessing the clinical sample.

\section{RESEARCH SUPPORT}

This project was supported by a grant (code PSI2016--76511-R) from the Agencia Estatal de Investigación (AEI) of the Spanish Government and Fondo Europeo de Desarrollo Regional of the European Union (FEDER, EU). These Departments had no 
role in the study design collection, analysis or interpretation of the data, writing the manuscript, or the decision to submit the paper for publication.

José J. López-Goñi, Javier Fernández-Montalvo, Alfonso Arteaga, Begoña Haro, (2019). Suicidal attempts among patients with substance use disorders who present with suicidal ideation. Addictive Behaviors 89, 5-9

https://doi.org/10.1016/j.addbeh.2018.09.006 


\section{REFERENCES}

American Psychiatric Association, 2013. Diagnostic and statistical manual of mental disorders (Fifth Edition). APA, Arlington, VA.

Arribas-Ibar, E., Suelves, J.M., Sanchez-Niubo, A., Domingo-Salvany, A., Brugal, M.T., 2017. Suicidal behaviours in male and female users of illicit drugs recruited in drug treatment facilities. Gaceta Sanitaria 31(4), 292-298.

Bobes, J., González, M.P., Saiz, P.A., Bousoño, M., 1996. Índice Europeo de Severidad de la Adicción: EuropASI. Versión española [European Index of Severity of Addiction: EuropASI. Spanish Version], in: Bobes García, J. (Ed.) Actas de la IV Reunión Interregional de Psiquiatría. Gijón, pp. 201-218.

Cacciola, J.S., Leggett, K., Camilleri, A.C., 2009. Treatment history: Relationship to treatment outcomes. Substance Use \& Misuse 44, 305-321.

Darke, S., Torok, M., Kaye, S., Ross, J., 2010. Attempted Suicide, Self-Harm, and Violent Victimization among Regular Illicit Drug Users. Suicide and Life-Threatening Behavior 40(6), 587-596.

Darvishi, N., Farhadi, M., Haghtalab, T., Poorolajal, J., 2015. Alcohol-Related Risk of Suicidal Ideation, Suicide Attempt, and Completed Suicide: A Meta-Analysis. Plos One 10(5).

Derogatis, L.R., 1992. The SCL-90-R. Clinical Psychometric Research, Baltimore. Fernández-Montalvo, J., López-Goñi, J.J., 2010. Comparison of completers and dropouts in psychological treatment for cocaine addiction. Addiction Research \& Theory 18(4), 433-441.

Fernández-Montalvo, J., López-Goñi, J.J., Arteaga, A., 2015. Psychological, physical and sexual abuse in addicted patients who undergo treatment. Journal of Interpersonal Violence 30(8), 1279-1298.

José J. López-Goñi, Javier Fernández-Montalvo, Alfonso Arteaga, Begoña Haro, (2019). Suicidal attempts among patients with substance use disorders who present with suicidal ideation. Addictive Behaviors 89, 5-9 
Fernández-Montalvo, J., López-Goñi, J.J., Arteaga, A., Haro, B., in press. Suicidal ideation and attempts among patients with lifetime physical and/or sexual abuse in treatment for substance use disorders. Addiction Research \& Theory.

Fernández-Montalvo, J., López-Goñi, J.J., Illescas, C., Landa, N., Lorea, I., 2008.

Evaluation of a therapeutic community treatment program: A long-term follow-up study in Spain. Substance Use \& Misuse 43(10), 1362-1377.

Garlow, S.J., Purselle, D., D'Orio, B., 2003. Cocaine use disorders and suicidal ideation. Drug and Alcohol Dependence 70(1), 101-104.

González de Rivera, J.L., 2002. Versión española del SCL-90-R [Spanish version of the SCL-90-R]. TEA, Madrid.

Hung, G.C.-L., Caine, E.D., Fan, H.-F., Huang, M.-C., Chen, Y.-Y., 2013. Predicting suicide attempts among treatment-seeking male alcoholics: An exploratory study.

Suicide and Life-Threatening Behavior 43(4), 429-438.

Kokkevi, A., Hartgers, C., 1995. European adaptation of a multidimensional assessment instrument for drug and alcohol dependence. European Addiction Research 1, 208-210. Lopez-Goni, J.J., Fernandez-Montalvo, J., Arteaga, A., 2012. Predictive validity of the EuropASI: Clinical diagnosis or composite scoring? Journal of Substance Abuse Treatment 42(4), 392-399.

López-Goñi, J.J., Fernández-Montalvo, J., Arteaga, A., 2012. Addiction treatment dropout: Exploring patients' characteristics. American Journal on Addictions 21(1), 7885.

López-Goñi, J.J., Fernández-Montalvo, J., Cacho, R., Arteaga, A., 2014. Profile of addicted patients who reenter treatment programs. Substance Abuse 35(2), 176-183. López-Goñi, J.J., Fernández-Montalvo, J., Menéndez, J.C., Yudego, F., García, A., Esarte, S., 2010. Group and individual change in the treatment of drug addictions: A 
follow-up study in Therapeutic Communities. Spanish Journal of Psychology 13(2), 906-913.

McLellan, A.T., Luborsky, L., Woody, G.E., O’Brien, C.P., 1980. An improved diagnostic evaluation instrument for substance abuse patients: The Addiction Severity Index. The Journal of Nervous and Mental Disease(168), 26-33.

Moos, R.H., Moos, B.S., Finney, J.W., 2001. Predictors of deterioration among patients with substance-use disorders. Journal of Clinical Psychology 57(12), 1403-1419. Rodriguez-Cintas, L., Daigre, C., Braquehais, M.D., Palma-Alvarez, R.F., Grau-Lopez, L., Ros-Cucurull, E., Rodriguez-Martos, L., Abad, A.C., Roncero, C., 2018. Factors associated with lifetime suicidal ideation and suicide attempts in outpatients with substance use disorders. Psychiatry Research 262, 440-445.

Roy, A., 2001. Characteristics of cocaine-dependent patients who attempt suicide. American Journal of Psychiatry 158(8), 1215-1219.

Roy, A., 2002. Characteristics of opiate dependent patients who attempt suicide. Journal of Clinical Psychiatry 63(5), 403-407.

Roy, A., 2003. Characteristics of drug addicts who attempt suicide. Psychiatry Research 121(1), 99-103.

Roy, A., 2009. Characteristics of Cocaine Dependent Patients Who Attempt Suicide. Archives of Suicide Research 13(1), 46-51.

Roy, A., 2010. Risk Factors for Attempting Suicide in Heroin Addicts. Suicide and Life-Threatening Behavior 40(4), 416-420.

Vaszari, J.M., Bradford, S., O'Leary, C.C., Ben Abdallah, A., Cottler, L.B., 2011. Risk factors for suicidal ideation in a population of community-recruited female cocaine users. Comprehensive Psychiatry 52(3), 238-246. 
Yuodelis-Flores, C., Ries, R.K., 2015. Addiction and suicide: A review. The American Journal on Addictions 24(2), 98-104.

José J. López-Goñi, Javier Fernández-Montalvo, Alfonso Arteaga, Begoña Haro, (2019). Suicidal attempts among patients with substance use disorders who present with suicidal ideation. Addictive Behaviors 89, 5-9

https://doi.org/10.1016/j.addbeh.2018.09.006 


\section{Table 1}

Comparisons of sociodemographic, consumption, and psychopathological variables

\begin{tabular}{|c|c|c|c|c|c|c|c|}
\hline & $\begin{array}{c}\text { All } \\
(N=149)\end{array}$ & $\begin{array}{c}\text { Suicidal } \\
\text { Ideation } \\
(n=90)\end{array}$ & $\begin{array}{c}\text { Suicide } \\
\text { Attempt } \\
(n=59)\end{array}$ & $X^{2}(d f)$ & $p$ & $w$ & $\begin{array}{c}(1-\beta \\
\text { err. } \\
\text { prob. })\end{array}$ \\
\hline & $N(\%)$ & $n(\%)$ & $n(\%)$ & & & & \\
\hline \multicolumn{8}{|l|}{ Gender } \\
\hline Male & 110 (73.8\%) & 70 (77.8\%) & 40 (67.8\%) & $1.8(1)$ & .175 & 0.13 & 0.19 \\
\hline Female & 39 (26.2\%) & $20(22.2 \%)$ & 19 (32.2\%) & & & & \\
\hline \multicolumn{8}{|l|}{ Marital status } \\
\hline Single & $82(55.0 \%)$ & 47 (52.2\%) & 35 (59.3\%) & & & & \\
\hline Married & 35 (23.5\%) & $25(27.8 \%)$ & $10(16.9 \%)$ & $2.3(2)$ & .311 & 0.11 & 0.15 \\
\hline Other & 32 (21.5\%) & $18(20.0 \%)$ & 14 (23.7\%) & & & & \\
\hline \multicolumn{8}{|l|}{ Substance } \\
\hline Alcohol & 73 (49.0\%) & $41(45.6)$ & $32(54.2 \%)$ & & & & \\
\hline Cocaine & $64(43.0 \%)$ & $39(43.3 \%)$ & 25 (42.4\%) & $3.3(2)$ & .203 & 0.16 & 0.27 \\
\hline Other & 12 (8.1\%) & $10(11.1 \%)$ & 2 (3.4\%) & & & & \\
\hline Delirium tremens & $11(7.5 \%)$ & $3(3.4 \%)$ & $8(13.8 \%)$ & $5.5(1)$ & .019 & 0.26 & 0.67 \\
\hline \multirow[t]{2}{*}{ Overdoses } & $25(17.0 \%)$ & $10(11.2 \%)$ & $15(25.9 \%)$ & $5.3(1)$ & .021 & 0.18 & 0.32 \\
\hline & $M(S D)$ & $M(S D)$ & $M(S D)$ & $t(d f)$ & $p$ & $d$ & \\
\hline Age & $37.6(8.5)$ & $37.4(7.9)$ & $38.0(9.3)$ & $0.4(146)$ & .667 & 0.07 & 0.11 \\
\hline Age at first alcohol consumption & $16.7(4.2)$ & $16.7(3.7)$ & $16.7(4.9)$ & $0.1(131)$ & .968 & 0.01 & 0.05 \\
\hline Years of alcohol consumption & $17.4(9.9)$ & $17.1(10.0)$ & $17.9(10.1)$ & $0.4(129)$ & .660 & 0.08 & 0.12 \\
\hline Age at first cocaine consumption & $22.7(6.4)$ & $23.5(6.2)$ & $21.5(6.7)$ & $1.5(98)$ & .144 & 0.30 & 0.58 \\
\hline Years of cocaine consumption & $8.2(6.1)$ & $7.9(5.4)$ & $8.8(7.1)$ & $0.7(96)$ & .465 & 0.15 & 0.21 \\
\hline \multicolumn{8}{|l|}{ EuropASI ISR } \\
\hline Medical & $2.6(1.7)$ & $2.5(1.6)$ & $2.8(1.8)$ & $1.2(147)$ & .237 & 0.20 & 0.28 \\
\hline Employment/ Support & $3.0(1.9)$ & $2.7(1.7)$ & $3.5(2.0)$ & 2.7 (147) & .009 & 0.44 & 0.82 \\
\hline Alcohol & $4.3(2.1)$ & $3.9(2.0)$ & $4.7(2.1)$ & $2.3(147)$ & .027 & 0.37 & 0.75 \\
\hline Drugs & $3.9(2.3)$ & $3.8(2.1)$ & $4.1(2.5)$ & $0.8(104.8)$ & .450 & 0.13 & 0.19 \\
\hline Legal & $2.0(1.8)$ & $1.9(1.4)$ & $2.2(2.2)$ & $1.0(89.2)$ & .301 & 0.19 & 0.25 \\
\hline Family/ Social & $4.5(1.8)$ & $4.2(1.7)$ & $5.0(1.8)$ & $2.8(146)$ & .006 & 0.46 & 0.86 \\
\hline Psychiatric & $4.4(1.6)$ & $3.8(1.3)$ & $5.2(1.6)$ & $5.6(147)$ & $<.001$ & 0.96 & 0.99 \\
\hline \multicolumn{8}{|l|}{ SCL-90-R } \\
\hline Global Severity Index & $72.3(31.9)$ & $69.8(32.7)$ & $76.0(30.5)$ & $1.2(147)$ & .248 & 0.19 & 0.31 \\
\hline Positive Symptom Distress Index & $54.9(32.7)$ & $53.4(33.1)$ & $57.1(32.2)$ & $0.7(147)$ & .490 & 0.12 & 0.17 \\
\hline Positive Symptom Total & 75.9 (29.5) & $73.1(30.8)$ & $80.3(27.3)$ & $1.5(134.3)$ & .139 & 0.24 & 0.43 \\
\hline Somatisation & $64.4(31.6)$ & $66.0(30.4)$ & $61.9(33.4)$ & $0.8(147)$ & .436 & 0.13 & 0.19 \\
\hline Obsession-compulsion & $67.2(32.6)$ & $63.7(33.9)$ & $72.6(30.0)$ & $1.6(147)$ & .105 & 0.27 & 0.50 \\
\hline Interpersonal sensitivity & 69.8 (32.9) & $67.7(32.7)$ & $72.9(33.1)$ & $0.9(147)$ & .342 & 0.16 & 0.24 \\
\hline Depression & $68.9(32.3)$ & $65.5(32.4)$ & $74.2(31.6)$ & $1.6(147)$ & .107 & 0.27 & 0.49 \\
\hline Anxiety & $67.6(32.6)$ & $63.9(33.8)$ & $73.1(30.2)$ & $1.7(133.7)$ & .089 & 0.28 & 0.52 \\
\hline Hostility & $56.8(32.5)$ & $57.2(32.7)$ & $56.2(32.7)$ & $0.2(147)$ & .855 & 0.03 & 0.07 \\
\hline Phobic anxiety & $59.3(37.5)$ & $54.3(38.1)$ & $66.9(35.6)$ & $2.1(147)$ & .045 & 0.34 & 0.65 \\
\hline Paranoid ideation & 66.9 (32.9) & $67.6(30.4)$ & $66.0(36.5)$ & $0.3(108.3)$ & .785 & 0.05 & 0.09 \\
\hline Psychoticism & $74.7(30.4)$ & $72.4(31.5)$ & $78.1(28.5)$ & $1.1(147)$ & .264 & 0.19 & 0.30 \\
\hline
\end{tabular}


Table 2

Comparisons of maladjustment variables

\begin{tabular}{|c|c|c|c|c|c|c|c|}
\hline & $\begin{array}{c}\text { All } \\
(N=149)\end{array}$ & $\begin{array}{l}\text { Suicidal } \\
\text { Ideation } \\
(n=90) \\
\end{array}$ & $\begin{array}{c}\text { Suicide } \\
\text { Attempt } \\
(n=59)\end{array}$ & \multirow[t]{2}{*}{$X^{2}(d f)$} & \multirow[t]{2}{*}{$p$} & \multirow[t]{2}{*}{$w$} & \multirow{2}{*}{$\begin{array}{c}(1-\beta \\
\text { err. } \\
\text { prob. })\end{array}$} \\
\hline & $N(\%)$ & $n(\%)$ & $n(\%)$ & & & & \\
\hline \multicolumn{8}{|l|}{ Medical maladjustment } \\
\hline Chronic problem interfering with life & $66(44.3 \%)$ & 35 (38.9\%) & $31(52.5 \%)$ & $2.7(1)$ & .101 & 0.15 & 0.24 \\
\hline Prescribed medication for a physical problem & $45(30.2 \%)$ & $19(21.1 \%)$ & $26(44.1 \%)$ & $8.9(1)$ & .003 & 0.24 & 0.60 \\
\hline \multicolumn{8}{|l|}{ Social maladjustment } \\
\hline \multicolumn{8}{|l|}{ Lack of close and long lasting relationships with } \\
\hline their partner (total sample) & $37(24.8 \%)$ & $18(20.0 \%)$ & $19(32.2 \%)$ & $2.8(1)$ & .092 & 0.14 & 0.22 \\
\hline their partner ( $\mathrm{n}=137$ with a partner) & $25(18.2 \%)$ & $10(12.2 \%)$ & $15(27.3 \%)$ & $5.0(1)$ & .025 & 0.21 & 0.45 \\
\hline their children (total sample) & $96(65.3 \%)$ & $58(65.9 \%)$ & $38(64.4 \%)$ & $0.1(1)$ & .851 & 0.03 & 0.06 \\
\hline their children ( $\mathrm{n}=57$ with children) & $6(10.5 \%)$ & $0(--)$ & $6(22.2 \%)$ & $7.4(1)$ & .006 & 0.35 & 0.50 \\
\hline \multicolumn{8}{|l|}{ Psychological maladjustment } \\
\hline Anxiety problems & $117(78.5 \%)$ & $64(71.1 \%)$ & $53(89.8 \%)$ & $7.4(1)$ & .007 & 0.23 & 0.54 \\
\hline Severe depression & 115 (77.2\%) & $64(71.1 \%)$ & $51(86.4 \%)$ & $4.8(1)$ & .029 & 0.19 & 0.39 \\
\hline Problems of violence control & $79(53.0 \%)$ & $43(47.8 \%)$ & 36 (61.0\%) & $2.5(1)$ & .113 & 0.15 & 0.23 \\
\hline Hallucinations & $32(21.5 \%)$ & 17 (18.9\%) & 15 (25.4\%) & $0.9(1)$ & .342 & 0.07 & 0.09 \\
\hline Psychopharmacological treatments & $101(68.2 \%)$ & $51(57.3 \%)$ & $50(84.7 \%)$ & $12.3(1)$ & $<.001$ & 0.31 & 0.83 \\
\hline Hospitalized for psychological problems $(\mathrm{n}=145)$ & $23(15.9 \%)$ & $4(4.6 \%)$ & $19(32.8 \%)$ & $20.7(1)$ & $<.001$ & 0.39 & 0.97 \\
\hline
\end{tabular}

José J. López-Goñi, Javier Fernández-Montalvo, Alfonso Arteaga, Begoña Haro, (2019).

Suicidal attempts among patients with substance use disorders who present with suicidal

ideation. Addictive Behaviors 89, 5-9 


\section{Table 3}

Logistic regression analysis

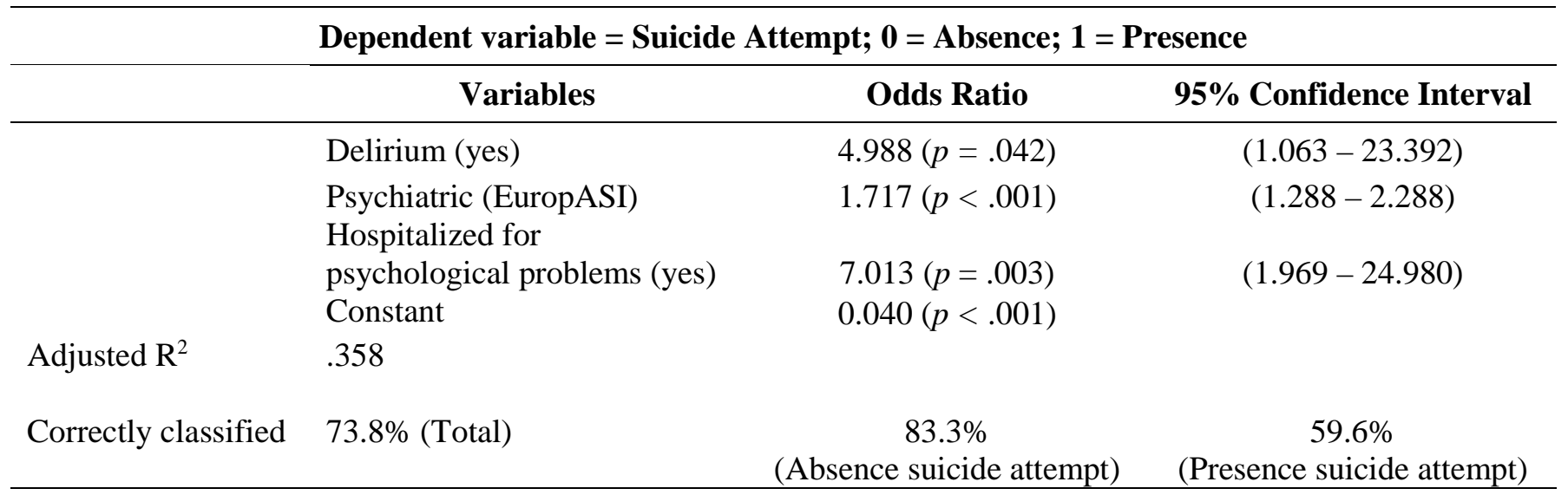

Note: All statistically significant variables in the bivariate comparisons were included in the logistic regression analysis. In this table the results of the final step are shown. 